\title{
Brucellosis in Camels and Humans: Seroprevalence and Associated Risk Factors in Amibara District of Afar Region, Ethiopia
}

\author{
Fekadu Gutema Wegi $\mathbb{D}^{1,2}{ }^{1,2}$ Kebede Amenu, ${ }^{2}$ Adugna Chalchisa, ${ }^{3}$ and Gezahegne Mamo ${ }^{2}$ \\ ${ }^{1}$ Animal Health Research Program, Holeta Agricultural Research Center, Ethiopian Institute of Agricultural Research, \\ P.O. Box 31, Holeta, Ethiopia \\ ${ }^{2}$ Department of Microbiology, Immunology and Veterinary Public Health, College of Veterinary Medicine and Agriculture, \\ Addis Ababa University, P.O. Box 34, Bishoftu, Ethiopia \\ ${ }^{3}$ Haramaya University, College of Veterinary Medicine, P.O. Box 138, Haramaya, Ethiopia
}

Correspondence should be addressed to Fekadu Gutema Wegi; fikadu881@gmail.com

Received 20 April 2021; Accepted 10 November 2021; Published 28 November 2021

Academic Editor: Carlos Alberto Hussni

Copyright $(2021$ Fekadu Gutema Wegi et al. This is an open access article distributed under the Creative Commons Attribution License, which permits unrestricted use, distribution, and reproduction in any medium, provided the original work is properly cited.

\begin{abstract}
Brucellosis is an important neglected zoonotic disease caused by infection with bacteria of the genus Brucella affecting different mammalian species including humans. A cross-sectional study was conducted to estimate the seroprevalence of brucellosis in camels and humans and its associated risk factors in Amibara District of Afar Region in Northeast Ethiopia, from October 2019 to May 2020. A total of 250 camel and 120 human sera were serially tested using the Rose Bengal plate test (RBPT) and complement fixation test (CFT). The overall seroprevalence of camel brucellosis in this study was 7.6\% (95\% CI: 4.9-11.56) by RBPT and 3.2\% (95\% CI: 1.63-6.2) by combined RBPT and CFT. In humans, twelve (10\%) of the collected sera were positive by RBPT among which only four of them (3.33\%) were positive by CFT. The risk factor analysis indicated that age, body condition, number of parity, and abortion history were significantly associated with Brucella seropositivity in camel $(P \leq 0.05)$. In humans, occupation and nonprotective handling of dystocia cases showed an apparent association with Brucella seropositivity. The results of this study indicated that brucellosis is a common health problem in camels and humans in Amibara District of Afar Region. The public health importance of this disease is associated with raw milk consumption and close contact with the animals having history of recent abortion. Therefore, controlling the risk factors, establishing Brucella diagnostic service in human clinics and hospitals, continuous social training with feedback assessments, and overall implementing of One Health approach framework to attain optimal health for people and domestic animals in area are recommended to safeguard the health of society.
\end{abstract}

\section{Introduction}

Brucellosis is a chronic bacterial disease, which affects numerous domestic and wild mammals with significant public health importance [1]. This disease critically hinders livestock productivity and imposes significant economic loss in the sector [2]. Cattle, camel, sheep, goat, pig, and dog are among the domestic animals that are greatly affected by this disease [3], whereas it is also documented in wildlife and marine animals [4]. The consumption of contaminated fetuses, meat, placentae, or milk is among the major attainment of brucellosis in domestic carnivores [5]. Currently, 11 Brucella species with high genetic similarity and each having different host preferences are recognized [6].

Among these, three Brucella spp., namely, B. abortus, B. melitensis, and B. suis, are known to have high zoonotic and economic importance [6]. Brucella organisms enter into the body of host through inhalation, ingestion, and mucous membrane or broken skin [7]. Brucellosis is found distributed all over the world [8] where greater prevalence is reported from Africa. In Ethiopia, it is found to be one of the endemic diseases of livestock, which is manifested by 
abortion, late first calving age, long calving interval, low herd fertility, and comparatively low milk production $[9,10]$. According to the report of Muma et al. [11] and Schelling et al. [12], cows infected with Brucella are three to four times more expected to abort than the unexposed cows. Besides, this disease posed a barrier to animal transit and largely constrained livestock trade [13].

In humans, brucellosis is a devastating disease that lacks pathognomonic symptoms [14], being a main public health threat, and imposed economic crisis in many countries [15]. Like in domestic and wild mammals, this disease spread among people through the consumption of unpasteurized contaminated milk, raw liver [16], and contact with infected tissues and discharge [17]. Veterinarians, slaughterhouse workers, and laboratory personnel are at great risk of exposure to this chronic disease [18]. Grounded on the nature of the disease, their habit of raw milk consumption, and close physical contact with animals, the pastoralists are at extreme risk of contracting brucellosis [19]. However, since pastoralists usually situate in an inaccessible area, the incidence and the control of brucellosis are ill understood in both humans and animals in the pastoral settings of subSaharan Africa [20]. In the pastoral region of Ethiopia, a relatively varying prevalence of brucellosis in both animals and humans has been reported by different authors [21]. According to Ref. [22], the occurrence rates of brucellosis in humans of pastoral and sedentary system origins were estimated at 160 and 28 per 100,000 persons in a year, respectively.

Even though many studies have been made on the seroprevalence of camel and human brucellosis, there is no clear understanding of the geographic pattern of the disease. Additionally, the public health implication of brucellosis in the pastoral areas of Afar Region has not been extensively studied and evaluated by diagnostic techniques rather than relying on survey works [22]. Hence, the availability of recent finding could aid in instituting proper control and prevention measures against this disease for animal owners and communities of the areas at large. Therefore, this study was made to estimate the seroprevalence of brucellosis in camels and exposed individuals and to investigate potential risk factors in Amibara District of Afar Region in Ethiopia.

\section{Materials and Methods}

2.1. Description of the Study Area. This study was conducted in Amibara District of Gabirasu Zone (Zone 3) of Afar Region in Ethiopia located in the Middle Awash Valley (Figure 1). Amibara District is about $250 \mathrm{~km}$ to the Northeast of Addis Ababa and has 19 kebeles with a total population of $\sim 102,327$ of which 56,810 were male and 45,517 are female [23]. The altitude of Amibara District is $740 \mathrm{~m}$ above sea level. Monthly based climatic data of fourteen years show that the average maximum and minimum temperature of the area is $34^{\circ} \mathrm{C}$ and $19^{\circ} \mathrm{C}$, respectively, and its annual total rainfall is about $571 \mathrm{~mm}$ [24]. The livestock population of the Amibara District is composed of 103, 959 cattle, 122, 526 goats, 48,043 sheep, 3,888 donkeys, and 39,995 camels [25].

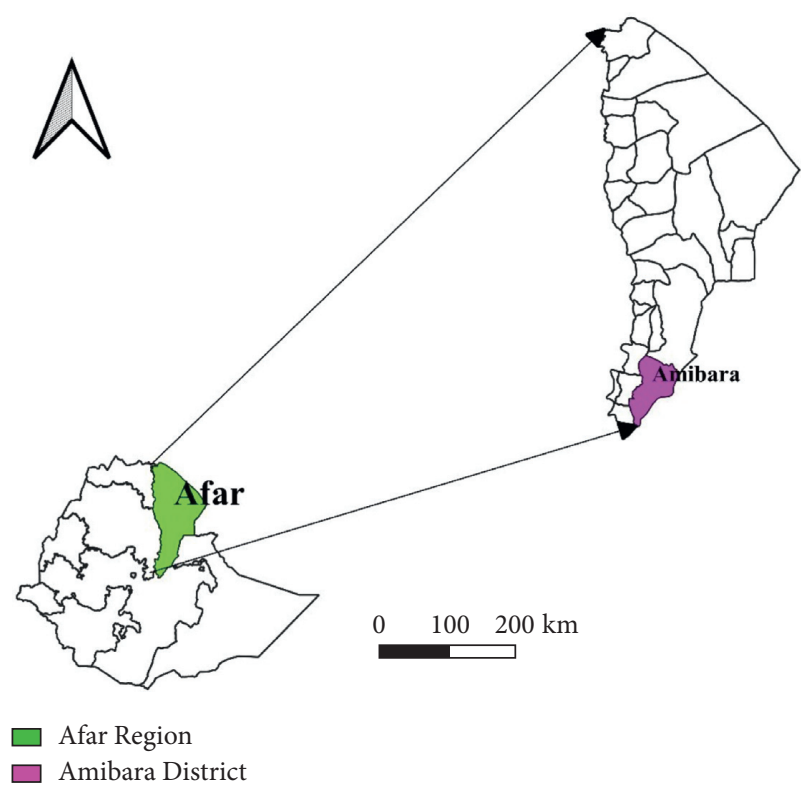

FIGURE 1: Map showing proposed study district. Source: Diva GIS.

2.2. Study Population. In the current study, the target study populations were nonvaccinated herds of Camelus dromedarius in the hands of pastoralists. Only camels older than six months of age were recruited into the study as the disease was not common in the animals less than 6 months of age. Camels' age was classified into $\leq 4 \mathrm{yrs}, 4-10 \mathrm{yrs}$, and $>10 \mathrm{yrs}$ as young, adult, and old age groups, respectively, according to [26]. To access the magnitude of public health impact, serum samples were also collected from the owners of the sampled camels.

2.3. Study Design and Sampling Techniques. A cross-sectional study design was employed from October 2019 to May 2020 in order to determine Brucella seroprevalence in both the camel and the owners of the sampled camel. Study kebeles were chosen purposively based on camel population and accessibility.

To select camel herds in the proposed kebeles, convenience sampling techniques were employed based on the willingness of herd owners to cooperate and accessibility during the period of study. Then, each herd was stratified into subgroups based on age and sex to ensure equal representation of all the subgroups. From each subgroup, individual animals were selected by systematic random sampling technique.

2.4. Sample Size Determination of Study Camels. The sample size for serodiagnosis of brucellosis in camel was estimated based on the prior study report in [26, 27] in Afar Region. Hence, the minimum required sample size was calculated using the formula described by [28], with defined $5 \%$ precision and $95 \%$ confidence level. Thus, by considering prior $4.1 \%$ seroprevalence report of camel brucellosis, the minimum required sample size was calculated to be 61 camels. However, to increase precision and minimize standard error, 
the required sample size obtained by calculation was augmented by fourfold. Hence, about 250 camels were considered for this study from selected kebeles of Amibara District.

\subsection{Determination of Sample Size of Human Participants.} To sample human participants, purposive sampling techniques were employed. Accordingly, all the owners of sampled camels were recruited into the study in which a maximum of four individuals were selected from each household based on their interest. Consequently, 120 individuals were included in this study.

2.6. Collection of Blood Sample from Study Camels. Blood samples were collected from each camel preceded by proper restraining to avoid unexpected personal injury and to minimize unnecessary stress that might happen to the animals. After disinfecting the site of jugular vein, $10 \mathrm{ml}$ of blood sample was collected into sterile plain vacutainer tube from each camel. Then, the samples were labeled using code describing herd number, sex, body condition, and kebeles. Then, the samples were taken to laboratory and serum was separated after maintaining at room temperature in slanted position for $24 \mathrm{hrs}$ and centrifuging at $1500 \mathrm{rpm}$ for 5 minutes in WARC. Finally, the serum was gently decanted into sterile cryovials $(1.8 \mathrm{ml})$, labeled, and stored at $-20^{\circ} \mathrm{C}$ until it gets transported to National Veterinary Institute (NVI), Serology Department, Bishoftu, Ethiopia.

In humans, about 5-7 $\mathrm{ml}$ of peripheral blood sample was collected from each respondent preceded by verbal agreement. Nurses working in Melka Werer Health Station collected blood samples from the human participants. Then, the sera were separated after allowing to stay in slanted position overnight at room temperature and centrifuging at $1500 \mathrm{rpm}$ for 5 minutes. Finally, the serum from each sample was poured into the cryovials $(1.8 \mathrm{ml})$, labeled, packed, and stored in WARC Animal Health Research Laboratory at $-20^{\circ} \mathrm{C}$.

2.7. Questionnaire Survey. In this study, the owners of the sampled camels and interested individuals were interviewed using a semistructured questionnaire. The questionnaire focused on the knowledge attitude and practice of the society about the zoonotic spread of brucellosis from camels to humans.

\subsection{Laboratory Diagnosis}

2.8.1. Rose Bengal Plate Test. In this study, camel sera were screened for brucellosis by RBPT at the National Veterinary Institute (NVI) of Ethiopia, but human sera were screened by RBPT at WARC and positive to RBPT was further confirmed by CFT at NVI. RBPT was conducted according to the procedures described by the World Organization for Animal Health [29]. B. abortus antigen (Lillidale Diagnostics, Holt, Wimborne, Dorset, BH21 7DG, United Kingdom) and their positive and negative control sera were utilized to detect the Brucella antibodies ensuing instructions of the manufacturers. Agglutinations were documented as $0,+,++$, and +++ , which designate the absence of agglutination, barely visible agglutination, fine agglutination, and coarse clumping, respectively [30]. The existence of agglutination at any mark was considered as positive reaction, while the absence of agglutination was considered as negative.

2.8.2. Complement Fixation Test (CFT). Serum samples reactive to $\mathrm{RBPT}$ were further tested by CFT for confirmation using standard B. abortus antigen S99 (New Haw, Addlestone, Surrey, KTI5, and 3NB-UK). The preparation of the reagent is evaluated by titration and was performed according to the protocol recommended by World Organization for Animal Health [31]. Sera with more than 75\% fixation of complement $(3+)$ at a dilution of $1: 5$ or at least with $50 \%$ fixation of complement $(2+)$ at a dilution of $1: 10$ and above were considered as positive result, whereas the lack of fixation/complete hemolysis was considered as negative result. Only samples that gave signals for both RBPT and CFT were considered positive since no single test is appropriate in all epidemiological situations due to problems of sensitivity and or specificity of the tests as recommended by OIE and other reports [32].

2.9. Data Analysis. Camel and human parameters, serological results, and questionnaire data were recorded in a Microsoft Excel ${ }^{\circledR}$ Spreadsheet, and the analysis was carried out using R Software version 4.0.0. Prevalence was calculated by dividing the number of positive animals and humans to the total number of animals and humans tested. Fisher's exact test was used to calculate the associations of risk factors with Brucella seropositivity. In this study, the numbers of outcomes of interest were less than $10 \%$ of the total sample size of camels and humans. Thus, Firth's bias-reduced logistic regression model was used to measure the association of potential risk factors with Brucella seropositivity [33]. Odds ratio (OR) was used to measure the degree of association between the risk factors such as herd size, age, sex, body condition, parity number, abortion history, and RFM with animal-level seroprevalence. $P$ value less than 0.05 was considered statistically significant in all analyses.

2.10. Ethical Consideration. The research ethical clearance for gathering of animal materials was approved by the Animal Research Ethical Review Committee of the College of Veterinary Medicine and Agriculture (CVMA) with certificate reference number of VM/ERC/03/01/12/2020. Pastoralists were also informed of the aim of the study, and their agreement was sought before the commencement of questionnaire data collection. For the collection of blood samples from the human participants, the work had earned recognition and written consent was obtained from Afar Regional Health Bureau by reference number of QAPB011/ 3934. 


\section{Result}

3.1. Seroprevalence of Camel Brucellosis and Associated Risk Factors. Of the 250 camel samples tested, 19 were positive by RBPT and 12 were confirmed by CFT. Thus, the overall seroprevalence of camel brucellosis in this study is $7.6 \%$ (95\% CI: $0.049-0.1156)$ by RBPT and $3.2 \%$ (95\% CI: $0.0163-0.062$ ) by combined RBPT and CFT. In Table 1, sexwise brucellosis seroprevalence and association of abortion with Brucella infection in camel were indicated. Accordingly, abortion history showed a statistically significant association with Brucella seropositivity $\left(P \leq 0.01^{*}\right)$, which means abortion in camels is mainly due to brucellosis. It was also indicated that female animals with abortion history were 36.2 times more tested positive for brucellosis than nonaborted animals $(\mathrm{OR}=36.2,95 \% \mathrm{CI}=7.52-351.9)$.

The association of possible risk factors with Brucella seropositivity in camel was indicated (Table 2). Consequently, no statistically significant difference in Brucella seropositivity was observed between both sexes of camel $(P>0.05)$. Additionally, age $(P \leq 0.004)$, history of abortion $(P \leq 0.005)$, body condition $(P \leq 0.003)$, and number of parity $(P \leq 0.001)$ were found to be significantly associated with Brucella seropositivity in camel. However, herd size and placental retention were considered and did not show significant association with brucellosis in camels $(P>0.05)$.

3.2. Multivariable Analysis of Risk Factors Associated with Brucellosis in Camel. Grounded on the multivariable Firth's bias-reduced logistic regression analysis, only history of abortion is independently associated with brucellosis in camel $(P \leq 0.002)$. Briefly, camels having history of abortion were 49.6 times more tested positive for brucellosis than those with no history of abortion. Camels with number of parity greater than 3 were also 2.75 times more at risk of contracting brucellosis than young camels (Table 3 ).

3.3. Serological Results of Human Brucellosis. Of 120 human sera tested by RBPT, 12 were found reactive among which only 4 confirmed by CFT to be Brucella seropositive. In this study, the occupation of the study participant showed a statistically significant association with Brucella seropositivity in humans $(P \leq 0.03)$ based on Fisher's exact test (Table 4).

3.4. Multivariable Analysis of Potential Risk Factors Associated with Brucella Seroprevalence in Humans. Following computation of univariable Firth's bias-reduced logistic regression analysis, all sociodemographic risk factors were insignificantly associated with Brucella seropositivity in humans. Moreover, individuals with nonpermanent work were 18.8 times more at risk of contracting brucellosis when compared with government employee and also showed a statistically significant association $\left(P \leq 0.03^{*}, 95 \% \mathrm{CI}: 1.324\right.$, 2730.32) with Brucella infection (Table 5).

\section{Results of Questionnaire Survey}

Questionnaires were administered to all 120 participants to gather information vis-à-vis their knowledge about zoonotic diseases and management of their livestock. Consequently, $80 \%$ of the respondents have no information of disease transmission from wild to domestic animals (Table 6). Moreover, $76.47 \%$ of the respondents were found to manage their animals by mixing different species, whereas the majority of them keep their animals in national park and practice inappropriate disposal of the aborted fetus and placental membrane, which are the major predisposing factors for the occurrence of brucellosis in cattle and camel (Table 6).

Moreover, consumption of raw meat and milk, knowledge of brucellosis, and other zoonotic diseases were considered and did not stand significantly $(P>0.05)$ with Brucella seropositivity in humans. Even though the statistical significance was not met, all seropositive individuals were consumers of raw milk, which elucidated that raw milk consumption is more associated with Brucella infection in the area. In this study, $90 \%$ of the respondents did not know about brucellosis and it comprises 10 positive animals and all reactive individuals. In this study, $91.7 \%$ of the respondents drink raw milk among which $3.63 \%$ of them tested positive for brucellosis (Table 7).

\section{Discussion}

Brucellosis is an infectious bacterial disease affecting all domestic and wild animals with significant economic and public health importance. In this study, the animal-based seroprevalence of camel brucellosis in Amibara District of Afar Region was $7.6 \%$ by RBPT and $3.2 \%$ by combined RBPT and CFT. Thus, this study revealed that the overall seroprevalence of camel brucellosis was 3.2\% (8/250).

This finding is comparable with the former reports of $3.1 \%$ in Yabello District of Borena Zone by Admasu et al. [34], 3.37\% in Mehoni District of Southeastern Tigray by Habtamu et al. [35], and 3\% in Southern lowland of Ethiopia by Jara et al. [36], but it is lower when compared to $5.7 \%$ in three camel rearing regions (Afar, Somali, and Borena) by Teshome et al. [37], 7.6\% in Awash Fentale and Amibara districts of Afar Region by Zewolda and Wereta [38], and $5.4 \%$ in four districts of Afar regional state by Bekele et al. [39]. This study result is also lower than some reports in other African and Middle East countries when compared with a prevalence of $30.5 \%$ in Sudan by Mokhtar et al. [40], $7.61 \%$ in Egypt by Hassanain and Ahmed [41], and 19.4\% in Jordan by Dawood [42]. 21.74\% (5/23) herd-level seroprevalence of camel brucellosis was recorded in this study, which is similar to the reports of [27] in Afar Region of Northeastern Ethiopia.

In this study, a higher number of Brucella seropositivity was seen in adults and older camels than in younger animals as it is a disease of sexually matured and pregnant animals, which agrees with the findings of Ref. [9]. The increased incidence of brucellosis in pregnant and sexually matured animals is associated with increased production of erythritol 
TABLE 1: Overall Brucella seroprevalence and association of abortion with the disease in camel.

\begin{tabular}{|c|c|c|c|c|c|}
\hline Variables & Number tested & No. of RBPT positive (\%) & No. of CFT positive (\%) & $P$ value & OR $(95 \% \mathrm{CI})$ \\
\hline Sex & & & & 0.814 & $0.7(0.075-91.85)$ \\
\hline Male & 9 & 1 & $0(0)$ & & \\
\hline Female & 223 & 18 & $8(3.2)$ & & \\
\hline Abortion history** & & & & $\leq 0.01^{*}$ & $36.2(7.52-351.9)$ \\
\hline Yes & 37 & $15(42.1)$ & $7(19.23)$ & & \\
\hline No & 204 & $4(3.4)$ & $1(0.284)$ & & \\
\hline
\end{tabular}

${ }^{* *}$ Only female animals were considered; ${ }^{*}$ significant.

TABLE 2: Summary of Brucella seropositivity in camels and association of potential risk factors.

\begin{tabular}{|c|c|c|c|c|c|}
\hline Variables & Number tested & Seropositive & Prevalence (\%) & $\chi^{2}$ & $P$ value \\
\hline Sex & & & & $0.309^{\mathrm{a}}$ & 1 \\
\hline Male & 9 & 0 & 0 & & \\
\hline Female & 241 & 8 & 3.43 & & \\
\hline Age & & & & $10.7^{\mathrm{b}}$ & $\leq 0.004^{*}$ \\
\hline Young & 34 & 0 & 0 & & \\
\hline Adult & 165 & 2 & 1.21 & & \\
\hline Old & 51 & 6 & 11.764 & & \\
\hline Body condition & & & & $10.26^{\mathrm{b}}$ & $\leq 0.003^{*}$ \\
\hline Poor & 53 & 6 & 11.3 & & \\
\hline Medium & 158 & 2 & 1.266 & & \\
\hline Good & 39 & 0 & 0 & & \\
\hline Herd size & & & & $0.926^{\mathrm{b}}$ & 0.6357 \\
\hline$<20$ & 42 & 2 & 4.76 & & \\
\hline $20-50$ & 92 & 2 & 2.17 & & \\
\hline$>50$ & 116 & 4 & 3.45 & & \\
\hline Number of parity** & & & & $11.2^{\mathrm{b}}$ & $\leq 0.001^{*}$ \\
\hline Null & 32 & 0 & 0 & & \\
\hline Less than or $=3$ & 160 & 2 & 1.25 & & \\
\hline Greater than 3 & 49 & 6 & 12.24 & & \\
\hline Abortion history ${ }^{* *}$ & & & & $29.96^{a}$ & $\leq 0.005^{*}$ \\
\hline Aborted & 37 & 7 & 18.92 & & \\
\hline No abortion & 213 & 1 & 0.47 & & \\
\hline Placental retention $^{* *}$ & & & & $0.134^{\mathrm{b}}$ & 1 \\
\hline Yes & 4 & 0 & 0 & & \\
\hline No & 229 & 8 & 3.5 & & \\
\hline
\end{tabular}

${ }^{\mathrm{b}}$ Fisher's exact test value; ${ }^{\mathrm{a}}$ chi-square value; ${ }^{*}$ significant; ${ }^{* *}$ only female animals considered.

TAвLE 3: Multivariable Firth's bias-reduced logistic regression analysis of factors associated with brucellosis seropositivity in camel.

\begin{tabular}{|c|c|c|c|c|c|}
\hline Variables & Number tested & Seropositive & Adjusted OR & $(95 \% \mathrm{CI})$ & $P$ value \\
\hline \multicolumn{6}{|l|}{ Parity number } \\
\hline Null & 32 & 0 & 1 & 1 & - \\
\hline Less than or $=3$ & 160 & 2 & 0.15 & $(-5.31,3.233)$ & 0.357 \\
\hline Greater than 3 & 49 & 6 & 2.75 & $(-195,6.00)$ & 0.511 \\
\hline \multicolumn{6}{|l|}{ Abortion history } \\
\hline Yes & 36 & 7 & 49.6 & $(2.148,6.34)$ & $\leq 0.002^{*}$ \\
\hline No & 205 & 1 & & 1 & - \\
\hline
\end{tabular}

1: reference

sugar at this stage of life, which enhances the multiplication of pathogen [26].

Herd size of the camels was also considered in this study to see the dynamics of this disease in different herd groups since it is known to be the disease of herd importance. However, no statistically significant difference $(P>0.05)$ in Brucella seropositivity was observed among different herd groups of camels based on Fisher's exact test even though this finding disagrees with the report of Ref. [26].

To boost the immunity of the host against various infectious diseases, diet plays a decisive role. Malnourished animals are likely to have poor body condition, which is revealed by decreased immunity, persistent occurrence of infection, and vulnerability to noninfectious organisms 
TABLE 4: Sociodemographic characteristics and Brucella seroprevalence among the study participants.

\begin{tabular}{|c|c|c|c|c|c|c|c|}
\hline \multirow{2}{*}{ Variables } & \multirow{2}{*}{ No. of tested $N(\%)$} & \multicolumn{2}{|c|}{$\mathrm{RBPT}+\mathrm{ve}$} & \multicolumn{2}{|c|}{ CFT + ve } & \multirow{2}{*}{$\chi^{2}$} & \multirow{2}{*}{$P$ value } \\
\hline & & $n$ & $\%$ & $n$ & $\%$ & & \\
\hline Gender & & & & & & & 0.19 \\
\hline Male & $95(79.2)$ & 8 & 8.4 & 2 & 2.1 & & \\
\hline Female & $25(20.8)$ & 4 & 16 & 2 & 8 & & \\
\hline Age & & & & & & $5^{\mathrm{b}}$ & 0.057 \\
\hline 13-19 years & $6(5)$ & 1 & 16.67 & 1 & 16.67 & & \\
\hline $20-59$ years & $79(65.8)$ & 6 & 7.6 & 1 & 1.26 & & \\
\hline Above 60 years & $35(29.17)$ & 5 & 14.3 & 2 & 5.71 & & \\
\hline Educational status & & & & & & $3.7^{\mathrm{b}}$ & 0.786 \\
\hline Degree & $1(0.83)$ & 0 & 0.0 & 0 & 0.0 & & \\
\hline Diploma & $3(2.5)$ & 0 & 0.0 & 0 & 0.0 & & \\
\hline High school & $10(8.33)$ & 0 & 0.0 & 0 & 0.0 & & \\
\hline Elementary & $16(13.34)$ & 2 & 12.5 & 1 & 6.25 & & \\
\hline Read and write & $9(7.5)$ & 1 & 11.1 & 0 & 0.0 & & \\
\hline Illiterate & $81(67.5)$ & 9 & 11.1 & 3 & 3.7 & & \\
\hline Occupation & & & & & & $6.925^{\mathrm{b}}$ & $\leq 0.03^{*}$ \\
\hline Pastoralists & $90(75)$ & 7 & 7.78 & 2 & 2.22 & & \\
\hline Government & $22(18.34)$ & 2 & 9.09 & 0 & 0.0 & & \\
\hline Others & $8(6.67)$ & 3 & 37.5 & 2 & 25 & & \\
\hline Marriage & & & & & & $2.6^{\mathrm{b}}$ & 0.484 \\
\hline Married & $102(85 \%)$ & 11 & 10.78 & 3 & 2.94 & & \\
\hline Divorced & $1(0.833)$ & 0 & 0.0 & 0 & 0.0 & & \\
\hline Single & $17(14.17)$ & 1 & 5.88 & 1 & 5.88 & & \\
\hline Family size & & & & & & $1.694^{\mathrm{b}}$ & 0.375 \\
\hline $1-2$ & $30(25)$ & 4 & 13.33 & 2 & 6.67 & & \\
\hline $3-5$ & $58(48.33)$ & 6 & 10.34 & 1 & 1.72 & & \\
\hline Above 6 & $32(26.67)$ & 2 & 6.25 & 1 & 3.12 & & \\
\hline
\end{tabular}

${ }^{\mathrm{b}}$ Fisher's exact test value; No. of tested $=$ number of tested individuals.

TAвLE 5: Multivariable Firth's bias-reduced logistic regression analysis of factors associated with brucellosis seropositivity in humans.

\begin{tabular}{|c|c|c|c|c|c|}
\hline Variables & No. of tested & Seropositive & Adjusted OR & $(95 \% \mathrm{CI})$ & $P$ value \\
\hline \multicolumn{6}{|l|}{ Occupation } \\
\hline Government & 22 & 0 & 1 & 1 & - \\
\hline Others & 8 & 2 & 18.85 & $(1.324,2730.32)$ & $\leq 0.03^{*}$ \\
\hline Pastoralists & 90 & 2 & 1.42 & $(0.11,197.86)$ & 0.817 \\
\hline
\end{tabular}

No. of tested $=$ number of individuals tested; $O R=$ odds ratio; 1 : reference.

under normal condition [43]; [44]. Taking this into account, body condition of the camels was considered to see the status of Brucella infection in different body condition scores. As a result, statistically significant higher seropositivity of brucellosis was observed in camels with poor body condition score than in camels with medium or good body condition score $(P \leq 0.01)$, whereas similar findings were also reported by Abebe et al. [9].

Human brucellosis is a more prevalent disease in the pastoral areas of different African and Asian countries [19]. In this study, an overall human Brucella seropositivity of $3.33 \%$ was identified by combined RBPT and CFT. This finding is fairly in agreement with the findings of Ref. [45] in Jimma University Hospital, [46] in Addis Ababa, [47] in Eastern Ethiopia, and [48] in Adami Tullu who reported $3.6 \%, 4.8 \%, 4.8 \%$, and $2.15 \%$, respectively. However, the result of this study is lower than the finding of Ref. [49] in Turkey and Ref. [50] in India who reported 5.4\% and $4.96 \%$, respectively.
However, it is higher than the finding of Ref. [51] in Bangladesh and Ref. [52] in western who reported 2.0\% and $1.2 \%$, respectively. In the pastoral and agropastoral areas, the prevalence of brucellosis in humans is greatly influenced by the status of the disease in animals [53]. Brucellosis occurrence significantly varies extensively between and with countries [54]. So, the possible justification for the variation of the current human Brucella seroprevalence from the previous report was due to the difference in the sample size, difference in the lifestyle of the society, type of diagnostic protocol employed, and socioeconomic status of the study population.

One research work conducted in Malaysia showed that males are at greater risk of contracting brucellosis since they are commonly involved in the handling of livestock and consume uncooked animal product, especially in the pastoral area [55]. However, the finding of this study indicated that gender is not significantly associated with brucellosis seropositivity and did not much with the report of the above 
TABLE 6: Zoonotic disease knowledge and livestock keeping practice of pastoralists in the study area.

\begin{tabular}{|c|c|c|c|}
\hline Variables & Response category & Frequency & $\%$ \\
\hline \multicolumn{4}{|c|}{ Do you think that diseases can get transmitted from animals to humans? } \\
\hline & Yes & 24 & 20 \\
\hline & No & 96 & 80 \\
\hline \multirow[t]{5}{*}{ How do you herd your animals? } & $(N=102)$ & & \\
\hline & Mix at gazing point & 78 & 76.47 \\
\hline & Mix at watering point & 7 & 6.86 \\
\hline & All separately & 22 & 21.57 \\
\hline & All together & 13 & 12.74 \\
\hline \multirow[t]{3}{*}{ Do you keep animals in national park?* } & $(N=90)$ & & \\
\hline & Yes & 80 & 88.89 \\
\hline & No & 10 & 11.11 \\
\hline \multirow[t]{3}{*}{ Frequent occurrence of abortion ${ }^{* *}$} & $(N=102)$ & & \\
\hline & Yes & 68 & 66.67 \\
\hline & No & 34 & 33.33 \\
\hline \multirow[t]{5}{*}{ Which animals frequently abort?** } & $(N=102)$ & & \\
\hline & Cattle & 15 & 14.7 \\
\hline & Camel & 9 & 8.82 \\
\hline & Small ruminant & 54 & 52.94 \\
\hline & No animal abort & 24 & 23.53 \\
\hline \multirow[t]{4}{*}{ Disposal of placental membrane and aborted fetus } & $(N=102)$ & & \\
\hline & Dispose properly & 5 & 4.9 \\
\hline & Throw it on open field & 83 & 81.37 \\
\hline & Report to CAHWS & 14 & 13.72 \\
\hline
\end{tabular}

${ }^{*}$ Only pastoralists considered; ${ }^{* *}$ only respondents having animals considered.

TABLE 7: Association of knowledge and practice of the camel owners with Brucella seropositivity.

\begin{tabular}{|c|c|c|c|c|c|}
\hline Variables & $\begin{array}{l}\text { Respondents } \\
\mathrm{n}(\%)\end{array}$ & $\begin{array}{l}\text { Positive animals owned } \\
(\%)\end{array}$ & $\begin{array}{c}\text { Positive respondents } \\
\mathrm{n}(\%)\end{array}$ & Fisher's value & $P$ value \\
\hline Do you drink raw milk? & & & & - & 1 \\
\hline Yes & $110(91.7)$ & $12(2.79)$ & $4(3.63)$ & & \\
\hline No & $10(8.3)$ & $0(0)$ & $0(0)$ & & \\
\hline Do you consume raw meat? & & & & - & 0.572 \\
\hline Yes & $27(22.5)$ & $3(0.69)$ & $1(3.7)$ & & \\
\hline No & $94(78.33)$ & $9(2.08)$ & $3(3.2)$ & & \\
\hline Do you know zoonotic diseases? & & & & - & 0.318 \\
\hline Yes & $34(28.33)$ & $8(1.85)$ & $2(5.88)$ & & \\
\hline No & $86(71.67)$ & $4(0.93)$ & $2(2.32)$ & & \\
\hline Do you know brucellosis? & & & & - & 1 \\
\hline Yes & $12(10)$ & $2(0.46)$ & $0(0.0)$ & & \\
\hline No & $108(90)$ & $10(2.32)$ & $4(3.7)$ & & \\
\hline Do you use PG during handling dystocia case? & & & & - & $\leq 0.05^{*}$ \\
\hline Yes & $12(10)$ & $2(0.46)$ & $2(16.67)$ & & \\
\hline No & $108(90)$ & $10(2.32)$ & $2(1.85)$ & & \\
\hline How do you shelter camels? & & & & $9.08^{\mathrm{b}}$ & $\leq 0.03^{*}$ \\
\hline All separately & $82(68.33)$ & $10(2.32)$ & $1(1.22)$ & & \\
\hline All sheltered together & $2(1.67)$ & $0(0.0)$ & $1(50)$ & & \\
\hline Some sheltered together & $24(20)$ & $2(0.46)$ & $2(8.33)$ & & \\
\hline No idea & $12(10)$ & $0(0)$ & $0(0)$ & & \\
\hline
\end{tabular}

CAHWs: community-based animal health workers; ${ }^{b}$ Fisher's exact test value; ${ }^{a}$ chi-square value; ${ }^{*}$ significant.

research finding in Malaysia. This may be due to small sample size of this study and shared responsibility among males and females of Afar pastoralists. More than $90 \%$ of people in Afar Region depend on pastoral activity, and they spend almost all their entire life with their animals. The main source of their food is also animals' origin, especially milk, which is commonly consumed without boiling. In this study, $96.4 \%$ of the respondents drink raw milk, which agrees with the findings of Ref. [56] who reported that the consumption of uncooked food plays a crucial role in the transmission of brucellosis in humans. Nonsignificant association of educational background with brucellosis seropositivity of the 
respondent was found in this study $(P>0.05)$ because of low basic infrastructure in the area aligned with mobile lifestyle of the society.

However, the study conducted in Kenya showed a high level of knowledge of brucellosis in pastoral communities where respondents testified brucellosis to be a zoonotic disease and abortion as its common indicator [57]. This might be due to the difference in the educational access and coverage in the pastoral area of the two countries. Even though the association between raw milk consumption and Brucella seropositivity is statistically not significant, all of the seropositive individuals were consumers of raw milk. 78.33\% $(n=94)$ of this study's participants told that they do not consume raw meat, which is mainly concerned with cultural issue. This shows that the rate of Brucella infection in this study area is greatly associated with drinking of raw milk and contact with infected animals compared with the consumption of uncooked meat.

During handling of dystocia cases, the majority of the respondents (98.2\%) reported that they used hand pulling techniques without using protective gloves (90\%). The study conducted by Eshetu et al. [47] indicated that brucellosis was 5.11 times more in those who had assisted animals during parturition than in those who did not. Regarding the management of aborted fetal membrane/aborted fetus and discharge, $83(81.37 \%)$ of the respondents told that they throw it on the field. Additionally, it was also encountered that pastoralists leave dead camel calf at home to show the mother camel every morning by considering that the activity will instinct milk letdown. So, these activities can be the major predisposing factors for the widespread occurrence of brucellosis in camels, other domestic animals, and owners. However, $4.9 \%$ of the respondents practiced proper disposal of the aborted fetal materials. In this study, about $90 \%$ of the respondents had never heard about brucellosis and $65 \%$ of them need to acquire detailed information about it. Finally, the major symptoms of brucellosis were reported to respondents and about $99.1 \%$ of them were interested in giving blood samples for screening of brucellosis.

\section{Conclusion and Recommendations}

Brucellosis is one of the most vital bacterial diseases of domestic and wild animals with substantial economic and public health importance. Both animals and humans can contract brucellosis through direct contact with infected animals and their excreta, ingestion of infected materials, and sometimes through aerosol transmission. The results of this study indicated that brucellosis is a common health problem in camels and humans in Amibara District of Afar Region. The public health importance of this disease is associated with raw milk consumption and close contact with the animals having history of recent abortion.

Therefore, based on the present finding, the following recommendations are worth mentioning:

(i) Requiring a comprehensive active assessment and surveillance studies to understand the distribution of brucellosis and its transmission dynamics at domestic-wild life interface and its zoonotic significance

(ii) Working to control risk factors, establishing Brucella diagnostic service in human clinics and hospitals, and implementing One Health approach framework to attain optimal health for people and animals

(iii) Enhancing the awareness level of the pastoral society about the public health and economic significance of brucellosis through training and workshop

(iv) Conducting detailed studies on isolation and characterization of circulating strain and biotypes in the area

\section{Data Availability}

The data used to support the findings of this study are available from the corresponding author upon request.

\section{Conflicts of Interest}

The authors declare that they have no conflicts of interest.

\section{Acknowledgments}

The work presented in this paper is a part of the author's MVSc thesis research [58]. Taking the accomplishment of this research work into consideration, the authors would like to acknowledge Ethiopian Institute of Agricultural Research for providing a research fund. The authors also grateful to Addis Ababa University College of Veterinary Medicine and Agriculture for facilitation of this research work and Institute of Pathobiology and National Veterinary Institute (NVI) for provision of laboratory service. The authors also acknowledge Department of MIVP at AAU, College of Veterinary Medicine and Agriculture, and Werer Agricultural Research Center for logistic provision and good cooperation. The authors also grateful to the field veterinarian and pastoralist for their unwavering cooperation during sample collection of this study. Finally, the authors would like to extend their cordial appreciation and respect to Prof. Gezahegn Mamo for his outstanding technical support and mentorship during the actual work of this research.

\section{References}

[1] CFSPH, "Brucellosis," Center for Food Security and Public Health, Iowa State University, Ames, IA, USA, 2018.

[2] B. Yasmin and S. A. Lone, "Brucellosis: an economically important infection," Journal of Medical Microbiology \& Diagnosis, vol. 4, pp. 703-2161, 2015.

[3] L. B. Lopes, R. Nicolino, and J. P. A. Haddad, "Brucellosis-risk factors and prevalence: a review," The Open Veterinary Science Journal, vol. 4, 2010.

[4] J. Godfroid, "Brucellosis in wildlife," Revue Scientifique et Technique de l'OIE, vol. 21, no. 2, pp. 277-286, 2002.

[5] M. Woldemeskel, "Zoonosis due to Bruella Suis with special reference to infection in dogs (Carnivores): a brief review," 
Open Journal of Veterinary Medicine, vol. 3, no. 3, pp. 213221, 2013.

[6] C. Mathew, M. Stokstad, T. B. Johansen et al., "First isolation, identification, phenotypic and genotypic characterization of Brucella abortus biovar 3 from dairy cattle in Tanzania," BMC Veterinary Research, vol. 11, no. 1, p. 156, 2015.

[7] J. Corbel, Brucellosis in Humans and Animals, WHO Press, Geneve, Switzerland, 2006.

[8] F. De Massis, K. Zilli, G. Di Donato et al., "Distribution of Brucella field strains isolated from livestock, wildlife populations, and humans in Italy from 2007 to 2015," PLoS One, vol. 14, 2019.

[9] G. Abebe, Y. Worku, G. Mamo, and S. Nazir, "Sero-prevalence and associated risk factors of brucellosis in camel at Akaki Abattoir, Central Ethiopia," Journal of Animal Research, vol. 7, no. 4, p. 617, 2017.

[10] B. Megersa, D. Biffa, F. Abunna, A. Regassa, J. Godfroid, and E. Skjerve, "Seroprevalence of brucellosis and its contribution to abortion in cattle, camel, and goat kept under pastoral management in Borana, Ethiopia," Tropical Animal Health and Production, vol. 43, no. 3, pp. 651-656, 2011.

[11] J. B. Muma, J. Godfroid, K. L. Samui, and E. Skjerve, "Influencia de la infección por Brucella en los abortos registrados en rebaños de ganado vacuno de razas tradicionales a proximidad de animales salvajes en la llanura del Kafue, Zambia," Revue Scientifique et Technique de l'OIE, vol. 26, no. 3, pp. 721-730, 2007.

[12] E. Schelling, C. Diguimbaye, S. Daoud et al., "Brucellosis and Q-fever seroprevalences of nomadic pastoralists and their livestock in Chad," Preventive Veterinary Medicine, vol. 61, no. 4, pp. 279-293, 2003.

[13] M. Yilma, G. Mamo, and B. Mammo, "Review on brucellosis sero-prevalence and ecology in livestock and human population of Ethiopia," Achievements in the Life Sciences, vol. 10, no. 1, pp. 80-86, 2016.

[14] M. Ducrotoy, W. J. Bertu, G. Matope et al., "Brucellosis in Sub-Saharan Africa: current challenges for management, diagnosis and control," Acta Tropica, vol. 165, pp. 179-193, 2017.

[15] J. Njeru, G. Wareth, F. Melzer et al., "Systematic review of brucellosis in Kenya: disease frequency in humans and animals and risk factors for human infection," BMC Public Health, vol. 16, pp. 853-15, 2016.

[16] F. Gutema and J. Tesfaye, "Review on camel brucellosis: public health importance and status in Ethiopia," Academic Research Journal of Agricultural Science and Research, vol. 7, pp. 513529, 2019.

[17] M. Bosilkovski, "Brucellosis: it is not only Malta!" in ZoonosesInfections Affecting Humans and Animals, pp. 287-315, Springer, Berlin, Germany, 2015.

[18] S. Esmaeili, S. R. Naddaf, B. Pourhossein et al., "Seroprevalence of brucellosis, leptospirosis, and Q fever among butchers and slaughterhouse workers in south-eastern Iran," PLoS One, vol. 11, Article ID e0144953, 2016.

[19] B. Abbas and H. Agab, "A review of camel brucellosis," Preventive Veterinary Medicine, vol. 55, no. 1, pp. 47-56, 2002.

[20] J. J. McDermott and S. M. Arimi, "Brucellosis in sub-Saharan Africa: epidemiology, control and impact," Veterinary $M i$ crobiology, vol. 90, no. 1-4, pp. 111-134, 2002.

[21] M. Yohannes, H. Degefu, T. Tolosa, K. Belihu, R. R. Cutler, and S. Cutler, "Brucellosis in Ethiopia," African Journal of Microbiology Research, vol. 7, pp. 1150-1157, 2013.

[22] B. Zerfu, G. Medhin, G. Mamo, G. Getahun, R. Tschopp, and M. Legesse, "Community-based prevalence of typhoid fever, typhus, brucellosis and malaria among symptomatic individuals in Afar Region, Ethiopia," PLoS Neglected Tropical Diseases, vol. 12, no. 10, Article ID e0006749, 2018.

[23] CSA, Projected Population of Ethiopia from 2011-2019, Central Statistics Agency of Ethiopia, Addis Ababa, Ethiopia, 2019.

[24] W. Chekol and A. Mnalku, "Selected physical and chemical characteristics of soils of the middle awash irrigated farm lands, Ethiopia," Ethiopian Journal of Agricultural Science, vol. 22, pp. 127-142, 2012.

[25] CSA, Agricultural Sample Survey 2006-07, Vol. 1, Central Statistics Agency of Ethiopia, , Addis Ababa, Ethiopia, 2007.

[26] F. Gizaw, G. Fentahun, S. Mersha, H. Bedada, M. Pal, and V. Kandi, "Seroprevalence and risk factors of brucellosis among camels belonging to selected districts of Afar, Ethiopia: need for public awareness," American Journal of Microbiological Research, vol. 5, no. 5, pp. 94-100, 2017.

[27] A. Hadush, M. Pal, T. Kassa, and F. Zeru, "Sero-epidemiology of camel brucellosis in the Afar region of Northeast Ethiopia," Journal of. Veterinary Medicine and Animal Health, vol. 5, pp. 269-275, 2013.

[28] M. Thrusfield, "Veterinary Epidemiology," Blackwell Science Ltd, Oxford, UK, 3rd edition, 2007.

[29] OIE, Brucellosis (B. abortus, B. Melitensis, and B. Suis, World Organisation for Animal Health, Paris, France, 2018.

[30] K. Nielsen, "Diagnosis of brucellosis by serology," Veterinary Microbiology, vol. 90, no. 1-4, pp. 447-459, 2002.

[31] OIE, Manual of Diagnostic Tests and Vaccines for Terrestrial Animals, World Organisation for Animal Health (OIE), Paris, France, 2008

[32] G. Tumwine, E. Matovu, J. D. Kabasa, D. O. Owiny, and S. Majalija, "Human brucellosis: sero-prevalence and associated risk factors in agro-pastoral communities of Kiboga District, Central Uganda," BMC Public Health, vol. 15, no. 1, p. 900, 2015.

[33] R. Puhr, G. Heinze, M. Nold, L. Lusa, and A. Geroldinger, "Firth's logistic regression with rare events: accurate effect estimates and predictions?" Statistics in Medicine, vol. 36, pp. 2302-2317, 2017.

[34] P. Admasu and G. Kaynata, "Seroprevalence of camel brucellosis in Yabello district of borena zone, southern Ethiopia," Journal of Veterinary Medicine and Research, vol. 4, p. 1115, 2017.

[35] T. T. Habtamu, B. Richard, H. Dana, and A. T. Kassaw, "Camel brucellosis: its public health and economic impact in pastoralists, Mehoni district, Southeastern Tigray, Ethiopia," Journal of Microbiology Research, vol. 5, pp. 149-156, 2015.

[36] R. Jara, M. Alemayehu, Z. Wubishet, T. Mesfin, and M. Araya, "Sero-prevalence and associated risk factors of camel brucellosis in southern lowland of Ethiopia," Journal of Veterinary Medicine and Research, vol. 7, pp. 1-8, 2020.

[37] H. Teshome, B. Molla, and M. Tibbo, "A seroprevalence study of camel brucellosis in three camel-rearing regions of Ethiopia," Tropical Animal Health and Production, vol. 35, no. 5, pp. 381-390, 2003.

[38] S. Zewolda and M. Wereta, "Seroprevalence of Brucella infection in camel and its public health significance in selected districts of Afar region, Ethiopia," Journal of Environmental and Occupational Science, vol. 1, no. 2, p. 91, 2012.

[39] W. A. Bekele, T. S. Tessema, and S. K. Melaku, "Camelus dromedarius brucellosis and its public health associated risks in the Afar National Regional State in northeastern Ethiopia," Acta Veterinaria Scandinavica, vol. 55, no. 1, p. 89, 2013. 
[40] M. Mokhtar, A. A. Abdelhamid, M. A. A. Sarah, and M. A. Abbas, "Survey of brucellosis among sheep, goats, camels and cattle in Kassala area, Eastern Sudan," Asian Journal of Animal and Veterinary Advances, vol. 6, pp. 635637, 2007.

[41] N. A. Hassanain and W. M. Ahmed, "Sero-prevalence of brucellosis in Egypt with emphasis on potential risk factors," World Journal of Medical Sciences, vol. 7, pp. 81-86, 2012.

[42] H. A. Dawood, "Brucellosis in Camels (Camelus dromedorius) in the south province of Jordan," American Journal of Agricultural and Biological Sciences, vol. 3, no. 3, pp. 623-626, 2008.

[43] A. Kamili, M. Bengoumi, and B. Faye, "Assessment of body condition and body composition in camel by barymetric measurements," Journal of Camel Practice and Research, vol. 13, no. 1, pp. 67-72, 2006.

[44] O. M. Radostits, C. C. Gay, K. W. Hincheliff, and P. D. Constable, Veterinary Medicine, Elsevier, Amsterdam, Netherlands, 10th edition, 2007.

[45] T. Tolosa, F. Regassa, K. Belihu, and G. Tizazu, "Brucellosis among patients with fever of unknown origin in Jimma University Hospital, Southwestern Ethiopia," Ethiopian Journal of Health Sciences, vol. 17, pp. 59-63, 2007.

[46] J. Kassahun, E. Yimer, A. Geyid et al., "Sero-prevalence of brucellosis in occupationally exposed people in Addis Ababa, Ethiopia," Ethiopian Medical Journal, vol. 44, pp. 245-252, 2006.

[47] A. Eshetu, D. Belina, M. Jafer, and S. Mengistu, "Seroprevalence of brucellosis in camels and febrile human patients attending health facilities in selected districts of Eastern Ethiopia," 2018.

[48] G. Tibesso, N. Ibrahim, and T. Tolosa, "Sero-prevalence of bovine and human brucellosis in Adami Tulu, central Ethiopia," World Applied Sciences Journal, vol. 31, pp. 776780, 2014.

[49] S. Vancelik, A. Guraksin, and A. Ayyildiz, "Seroprevalence of human brucellosis in rural endemic areas in eastern Turkey," Tropical Doctor, vol. 38, no. 1, pp. 42-43, 2008.

[50] H. K. Sharma, S. K. Kotwal, D. K. Singh, M. A. Malik, and A. Kumar, "Seroprevalence of human brucellosis in and around Jammu, India, using different serological tests," Veterinary World, vol. 9, p. 742, 2016.

[51] A. K. M. A. Rahman, D. Berkvens, C. Saegerman et al., "Seroprevalence of brucellosis in patients with prolonged fever in Bangladesh," Journal of Infection in Developing Countries, vol. 10, pp. 939-946, 2016.

[52] M. Haileselassie, S. Kalayou, M. Kyule, M. Asfaha, and K. Belihu, "Effect of Brucella infection on reproduction conditions of female breeding cattle and its public health significance in Western Tigray, northern Ethiopia," Veterinary Medicine International, vol. 2011, Article ID 354943, 7 pages, 2011.

[53] M. M. Omer, M. T. Musa, M. R. Bakhiet, and L. Perrett, "Brucellosis in camels, cattle and humans: associations and evaluation of serological tests used for diagnosis of the disease in certain nomadic localities in Sudan," Revue Scientifique et Technique, vol. 29, pp. 669-663, 2010.

[54] M. Khan and M. Zahoor, "An overview of brucellosis in cattle and humans, and its serological and molecular diagnosis in control strategies," Travel Medicine and Infectious Disease, vol. 3, no. 2, 65 pages, 2018.

[55] B. Y. Tay, N. Ahmad, R. Hashim, K. L. Thong, X. P. Koh, and A. M. Noor, "Multiple-locus variable-number tandem-repeat analysis (MLVA) genotyping of human Brucella isolates in Malaysia," BMC Infectious Diseases, vol. 15, p. 220, 2015.

[56] J.-B. Ntirandekura, L. E. Matemba, H. A. Ngowi, S. I. Kimera, and E. D. Karimuribo, "Knowledge, perceptions and practices regarding brucellosis in pastoral communities of Kagera Region in Tanzania," Journal of Advanced Veterinary and Animal Research, vol. 5, pp. 343-353, 2018.

[57] M. Obonyo and W. B. Gufu, "Knowledge, attitude and practices towards brucellosis among pastoral community in Kenya, 2013," International Journal of Innovation and Regional Development, vol. 4, pp. 375-384, 2015.

[58] F. Gutema, "Brucellosis in cattle, camel and human: seroprevalence and associated risk factors in Amibara district of Afar Region, Ethiopia," MVsc Thesis, Addis Ababa University, Addis Ababa, Ethiopia, 2019. 